\title{
Prevention of the immediate intraocular pressure rise following argon laser trabeculoplasty
}

\author{
TIMOTHY W METCALFE AND DAVID E ETCHELLS \\ From the Department of Ophthalmology, Bradford Royal Infirmary, Duckworth Lane, Bradford BD96RJ
}

SUMMARY A prospective, randomised double-masked study was undertaken to compare the effect of pretreatment with acetazolamide or placebo on the immediate intraocular pressure (IOP) rise following argon laser trabeculoplasty. One hundred eyes (100 patients) underwent $180^{\circ}$ of laser treatment with a mean of 59 spots of $50 \mu \mathrm{m}$ size and 800 to $1000 \mathrm{~mW}$ power. The IOP was measured during the first three hours after laser treatment, at 24 hours, and at two months. Forty-six patients $(92 \%)$ in the placebo group had an immediate rise of IOP. The mean rise (SD) for these patients was $8.6(7 \cdot 1) \mathrm{mmHg}$. Fifteen patients $(30 \%)$ in this group had an IOP rise of greater than $10 \mathrm{mmHg}$. Nine patients $(18 \%)$ receiving acetazolamide had an immediate rise of IOP. The mean rise for these patients was $4 \cdot 3(3 \cdot 1) \mathrm{mmHg}$, and no patient had an increase in IOP of greater than $8 \mathrm{mmHg}$. Acetazolamide appears to be effective in preventing a critical IOP rise after argon laser trabeculoplasty $(\mathrm{p}<0 \cdot 0001)$.

Argon laser trabeculoplasty has gained widespread acceptance as a valuable tool for the control of glaucoma. Its efficacy in the short term has been established, ${ }^{12}$ and recent reports are encouraging with regard to long term control. ${ }^{3-7}$ Its mode of action has not been clearly elucidated, though an increase in outflow facility has been demonstrated. ${ }^{18-11}$ A variety of complications of laser trabeculoplasty have been reported, ${ }^{12-16}$ the most serious being an immediate rise in intraocular pressure. Eyes already severely compromised by chronically raised intraocular pressure are susceptible to further damage from acute pressure elevations which may lead to field loss or loss of central vision. ${ }^{12} 141517$

It has been suggested that the extent of trabecular meshwork treated, as well as the number of burns, their energy, and placement, have a bearing on the degree of the pressure rise; though attention to these details may reduce the incidence of raised pressure, they do not eradicate it. ${ }^{10-20}$ Several forms of pretreatment, including topical $4 \%$ pilocarpine, ${ }^{21}$ ALO 2145 (para-aminoclonidine), ${ }^{22} 23$ oral glycerin,,$^{24}$ and oral acetazolamide, ${ }^{25}$ have been reported to reduce

Correspondence to $T$ W Metcalfe, FRCS, Department of Ophthalmology, Leeds General Infirmary, Great George Street, Leeds LS1 3EX. the frequency and severity of the pressure rise, while pretreatment with topical corticosteroid, ${ }^{26}$ indomethacin, ${ }^{27-31}$ and flurbiprofen ${ }^{3131}$ had no statistically significant effect.

We performed a prospective, randomised, doublemasked study to evaluate the effectiveness of oral acetazolamide in preventing this pressure rise. A significant rise of IOP after argon laser trabeculoplasty is usually apparent by two hours, peaking between two and three hours and then declining; rarely a rise is first detected beyond this time..$^{132-34}$ Oral acetazolamide reaches a peak plasma concentration one hour after administration of the drug (Fig. 1), the greatest fall in IOP occurs after two hours (Fig. 2) and declines only slightly up to six hours. ${ }^{35}{ }^{36}$ Administration of acetazolamide one hour before argon laser trabeculoplasty should produce maximum IOP reduction to coincide with the period of potential maximum IOP elevation.

\section{Patients and methods}

In this controlled study all patients were white, aged 65 or over, and had uncontrolled open-angle glaucoma as defined by an IOP greater than $21 \mathrm{mmHg}$ and progressive visual field loss. All were on the maximum tolerated topical therapy and none were 


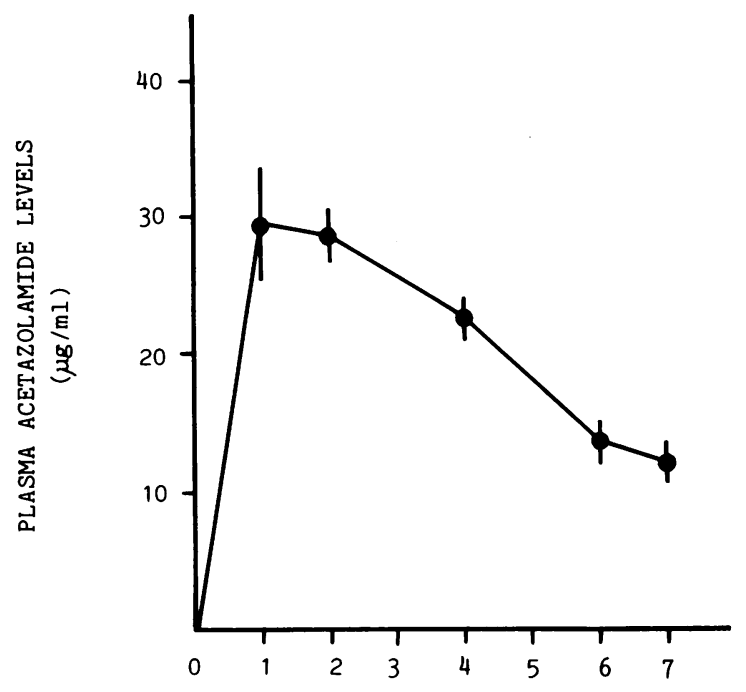

HOURS

Fig. 1 Average plasma concentration (with SE) following oral administration of acetazolamide $500 \mathrm{mg}$ in ocular hypertensive patients. Modified with permission from Friedland $B R$ et al. ${ }^{35}$

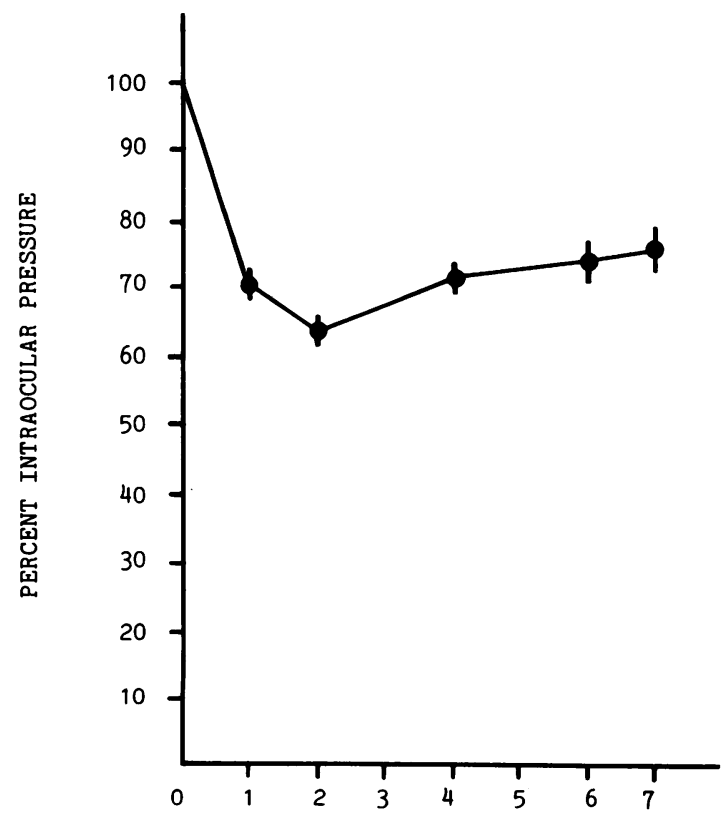

HOURS

Fig. 2 Percentage (SE) of initial IOP following oral administration of acetazolamide $500 \mathrm{mg}$. Modified with permission from Friedland $B R$ et al. ${ }^{35}$ receiving acetazolamide, which in our experience is poorly tolerated in this age group. One eye of each patient was included in the study. None had previously undergone laser trabeculoplasty. If bilateral treatment was required, the eye treated first was included. Informed consent was obtained from all patients.

Before each treatment the patients underwent ophthalmic assesment of both eyes, which included best corrected Snellen visual acuity, slit-lamp examination of the anterior segment, and applanation tonometry. The patient was then randomly selected to receive either two $250 \mathrm{mg}$ tablets of acetazolamide (group 1) or two placebo tablets (group 2). The medication selected was masked to both the patient and the physician. Acetazolamide or placebo were given orally, and one hour later the IOP was measured again immediately before argon laser trabeculoplasty. Topical anaesthesia was given with $0.4 \%$ oxybuprocaine. An antireflective Goldmann three-mirror contact lens was used to view the trabecular meshwork. A mean of 59 (SD 4.4) laser burns of 800 to $1000 \mathrm{~mW}$ power, $50 \mu \mathrm{m}$ spot size, and $0 \cdot 1$ second duration were applied to the anterior trabecular meshwork. The burns were applied evenly over $180^{\circ}$, and the power was titrated to achieve blanching of the meshwork with occasional bubble formation. Blue-green argon laser light was used for all treatments and was delivered by a Coherent model 900 laser. The power output of the laser was measured at the start of the study and found to be $95 \%$ of the laser meter reading. All the laser treatments were applied by one of the authors (TM) and all examinations were conducted by the other (DE).

After laser treatment the IOP in both eyes and the degree of anterior segment inflammation in the treated eye were determined at 30 minutes, one hour, two hours, three hours, and 24 hours by the classification of Kimura et al ${ }^{37}$ Excessive intraocular pressure elevation was treated with $500 \mathrm{mg}$ of intravenous acetazolamide and the patient monitored until the IOP had returned to baseline levels. An excessive IOP rise was defined as an increase of more than $30 \%$ or $10 \mathrm{mmHg}$ above pretreatment levels provided the peak IOP was greater than $30 \mathrm{mmHg}$, after Krupin et al. ${ }^{32}$ Following laser trabeculoplasty the patients continued all their initial antiglaucomatous treatment with additional prednisolone $0.5 \%$ eye drops four times a day for three days. A further IOP check was made at two months.

Statistical data are reported as mean and SD, and were analysed by Student's $t$ test, Fisher's exact test, Spearman's rank correlation coefficient, and multivariate regression analysis where appropriate. Values of p less than 0.05 were considered significant. 


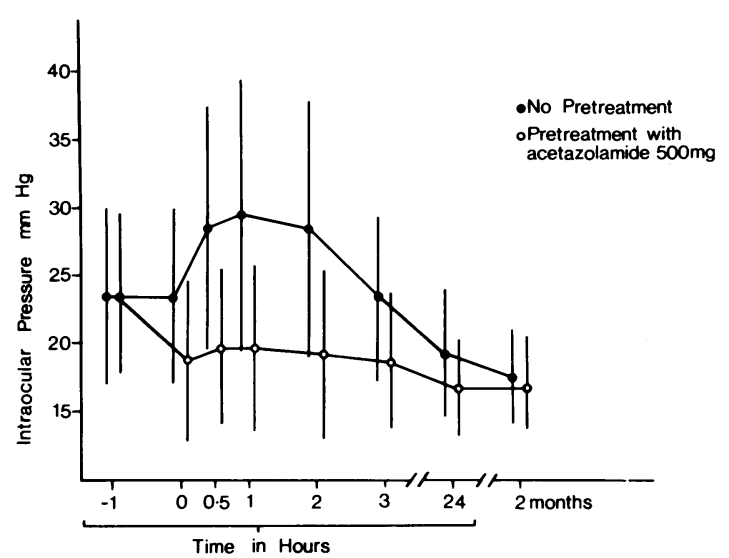

Fig. 3 Mean intraocular pressure (SD) before and after argon laser trabeculoplasty in patients receiving either acetazolamide (group 1) or placebo (group 2) pretreatment.

\section{Results}

One hundred eyes of 100 patients were treated. The mean age of group 1 was 74.0 years (SD 6.0) and of group 2 was 74.6 years (SD 5.9). The sex ratios were 27 female and 23 male in group 1 , and 26 female and 24 male in group 2. None of the patients had secondary glaucoma or chronic narrow-angle glaucoma. Six patients in group 1 and seven in group 2 had pseudoexfoliative glaucoma; the remaining patients had chronic open-angle glaucoma. The mean pretreatment IOP in group 1 was $23.6(6 \cdot 1)$ $\mathrm{mmHg}$ and in group $223.7(6 \cdot 5) \mathrm{mmHg}$. There was

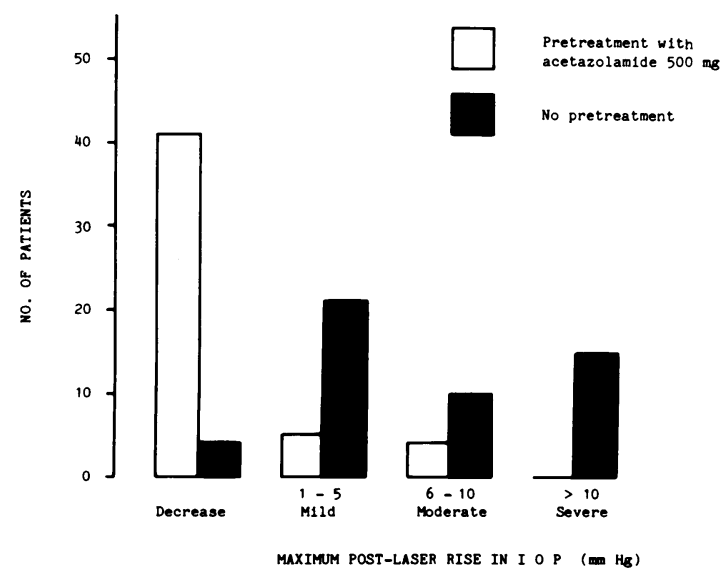

Fig. 4 Maximum intraocular pressure change following argon laser trabeculoplasty in patients receiving either acetazolamide (group 1) or placebo (group 2) pretreatment. Distribution is significantly different $(p<0 \cdot 0001)$.
Table 1 Time elapsed from laser trabeculoplasty at which maximum IOP rise occurred

\begin{tabular}{lrrrrrrr}
\hline Time (hours) & $0 \cdot 5$ & 1 & 2 & 3 & 24 & \\
\hline Number of patients & & & & & & Total \\
\hline Group 1 (acetazolamide) & 2 & 3 & 3 & 1 & 0 & 9 \\
Group 2 (placebo) & 13 & 19 & 13 & 0 & 1 & 46 \\
\hline
\end{tabular}

no significant difference between the mean pretreatment IOPs of the two groups $(p>0 \cdot 3)$. Two patients in each group had a pretreatment IOP greater than 35 $\mathrm{mmHg}$. The mean (with SD) IOPs before and after laser treatment at each examination time are presented in Fig. 3. The mean pressures were significantly lower in the acetazolamide pretreated patients (group 1) from time zero to 24 hours $(p<0.001$ at time zero, 30 minutes, one, two, and three hours, and $\mathrm{p}<0.01$ at 24 hours). There was no significant difference at two months $(\mathrm{p}>0 \cdot 3)$.

The numbers of patients in each group showing either a decrease or a mild, moderate, or severe increase in postlaser IOP are represented in Fig. 4, and the time at which the maximum IOP increase occurred is shown in Table 1. One patient with pseudoexfoliative glaucoma in group 2 experienced a rise of $5 \mathrm{mmHg}(21 \%)$ over the pretreatment IOP at 24 hours; in all other cases the maximum increase had occurred by three hours. Nine patients $(18 \%)$ in group 1 had a postlaser rise in IOP ranging from 1 to 8 $\mathrm{mmHg}$, mean $4 \cdot 3$ (SD 3.1) $\mathrm{mmHg}$. The mean rise for the group as a whole was $0 \cdot 8(2 \cdot 1) \mathrm{mmHg}$. None of the rises in pressure were significant as defined by Krupin et al. ${ }^{32}$ In group 246 patients (92\%) had a postlaser rise in pressure, the range being 1 to 25 $\mathrm{mmHg}$, mean $8.6(7 \cdot 1) \mathrm{mmHg}$. The mean rise for the group as a whole was $7.8(7 \cdot 2) \mathrm{mmHg}$. Fifteen patients $(30 \%)$ had a significant increase in IOP as defined by Krupin et al. ${ }^{32}$ In these patients intravenous acetazolamide was administered and produced satisfactory reduction in IOP in all cases.

There was a highly significant increased risk of an immediate postlaser IOP rise in group 2 compared with group $1(\mathrm{p}<0.0001$, Fisher's exact test $)$. The amplitude of the rise was also significantly higher in group $2(p<0 \cdot 01)$. We found no significant difference in the risk of a critical postlaser pressure rise between patients with pseudoexfoliation and those without $(p>0 \cdot 3$, Fisher's exact test). There was no significant difference in the pressure drop at two months between the two groups; the mean pressure drop for group 1 was $6 \cdot 8(4 \cdot 9) \mathrm{mmHg}$ and for group $26 \cdot 2(5 \cdot 5)$ $\mathrm{mmHg}$. An excessive postlaser rise in intraocular pressure did not significantly compromise the result- 
ing IOP at two months (Spearman's rank correlation coefficient).

Stepwise multivariate regression analysis showed there was no correlation between the postlaser pressure rise and age, sex, pretreatment IOP, previous antiglaucoma medication, number of burns administered, or postlaser inflammatory score. It also established that the only variable significantly to affect the pressure drop at two months was the initial IOP: the greater the initial IOP the greater the fall in IOP. This concurs with the findings of other authors. ${ }^{15} 16$

\section{Discussion}

The risk of an intraocular pressure rise immediately after laser trabeculoplasty has been widely reported and is confirmed by our study. The cause of the rise has not been elucidated. It has been suggested that prostaglandins released as part of the inflammatory response following laser trabeculoplasty may be the cause, as certain prostaglandins applied topically have been shown to increase the IOP ${ }^{3 \times}$ However, prostaglandin inhibitors have shown no beneficial effect. $^{26-31}$ Inflammatory debris silting up the trabecular meshwork has been implicated, but our study and others have found no correlation between inflammatory scores and postlaser IOP rises. ${ }^{27}{ }^{30.31}$ It seems more probable that localised structural changes and oedema in the trabecular meshwork resulting from the laser burn temporarily reduce aqueous outflow, leading to a rise in IOP. This may be aggravated by an exudative response of the damaged trabecular cells producing a transient pseudomembrane, ${ }^{39}$ further blocking egression of aqueous.

All investigators agree that an acute increase in intraocular pressure is deleterious and can lead to further loss of visual field or loss of central vision in a glaucomatous eye. Although Hoskins et al..$^{13} \mathrm{did}$ not find pretreatment with acetazolamide effective, we agree with Brooks et al. ${ }^{25}$ that acetazolamide confers a high degree of safety. Our results of a large prospective, randomised series showed that pretreatment with $500 \mathrm{mg}$ of oral acetazolamide is effective in decreasing both the frequency and the magnitude of the immediate IOP rise after argon laser trabeculoplasty. Pretreatment with acetazolamide had no effect on the results of argon laser trabeculoplasty at two months. None of our patients reported side effects from acetazolamide beyond slight paraesthesiae and mild gastrointestinal disturbance.

This study shows that the safe and widely available drug acetazolamide is of major value in preventing an acute pressure rise in patients undergoing argon laser trabeculoplasty.
We thank Dr David Jerwood, of the Bradford University Department of Mathematics and Statistics, for assistance with the statistical analysis.

Neither of the authors has any financial, commercial, or proprietary interest in acetazolamide.

\section{References}

1 Thomas JV, Simmons RJ, Belcher CD. Argon laser trabeculoplasty in the presurgical glaucoma patient. Ophthalmology 1982: 89: 187-97.

2 Greenidge KC. Spaeth GL, Fiol-Silva Z. Effect of argon laser trabeculoplasty on the glaucomatous diurnal curve. Ophthalmology 1983: 90: 800-4.

3 Grinich NP, Van Buskirk EM. Samples JR. Three-year efficacy of argon laser trabeculoplasty. Ophthalmology 1987: 94: 858-61.

4 Wise JB. Ten year results of laser trabeculoplasty. Does the laser avoid glaucoma surgery or merely defer it? Eye 1987: 1: 45-50.

5 Schwartz AL. Love DC. Schwartz MA. Long term follow-up of argon laser trabeculoplasty for uncontrolled open-angle glaucoma. Arch Ophthalmol 1985; 103: 1482-4.

6 Schwartz AL. Kopelman J. Four year experience with argon laser trabecular surgery in uncontrolled open-angle glaucoma. Ophthalmology 1983; 90: 771-80).

7 Shingleton BJ, Richter CU, Bellows AR. Hutchinson BJ, Glynn RJ. Long-term efficacy of argon laser trabeculoplasty. Ophthalmology 1987: 94: 1513-8.

8 Schwartz AL. Whitten ME. Bleiman B. Martin D. Argon laser trabecular surgery in uncontrolled phakic open angle glaucoma. Ophthalmology 1981: 88: 203-12.

9 Wilensky JT. Jampol LM. Laser therapy for open-angle glaucoma. Ophthalmology 1981; 88: 213-7.

10 Pohjanpelto P. Argon laser treatment of the anterior chamber angle for increased intraocular pressure. Acta Ophthalmol (Khh) 1981: 59: 211-20.

11 Brubaker RF, Liesegang TJ. Effect of trabecular photocoagulation on the aqueous humor dynamics of the human eye. $\mathrm{Am} \mathrm{J}$ Ophthalmol 1983; 96: 139-47.

12 Thomas JV, Simmons RJ, Belcher CD. Complications of argon laser trabeculoplasty. Glaucoma 1982: 4: 50-2.

13 Hoskins HD, Hetherington J, Minckler DS, Lieberman MF, Shaffer RN. Complications of laser trabeculoplasty. Ophthalmology 1983; 90: 796-9.

14 Levene R. Major early complications of laser trabeculoplasty. Ophthalmic Surg 1983; 14: 947-53.

15 Weinreb RN, Wilensky JT. Clinical aspects of argon laser trabeculoplasty. Int Ophthalmol Clin 1984: 24: 79-95.

16 Thomas JV. Simmons RJ, Belcher CD, Simmons RB. Laser trabeculoplasty: technique, indications, results, and complications. Int Ophthalmol Clin 1984: 24: 97-120.

17 Weinreb RN, Ruderman J, Juster R, Zweig K. Immediate intraocular pressure response to argon laser trabeculoplasty. Am J Ophthalmol 1983: 95: 279-86.

18 Rosenblatt MA, Luntz MH. Intraocular pressure rise after argon laser trabeculoplasty. Br J Ophthalmol 1987; 71: 772-5.

19 Rouhiainen HJ, Terasvirta ME, Tuovinen EJ. Laser power and postoperative intraocular pressure increase in argon laser trabeculoplasty. Arch Ophthalmol 1987; 105: 1352-4.

20 Wilensky JT, Weinreb RN. Low-dose trabeculoplasty. Am J Ophthalmol 1983: 95: 423-6.

21 Ofner SBS. Samples JR, Van Buskirk EM. Pilocarpine and the increase in intraocular pressure after trabeculoplasty. $A m J$ Ophthalmol 1984: 102: 647-9.

22 Robin AL, Pollack IP. House B, Enger C. Effects of ALO 2145 on intraocular pressure following argon laser trabeculoplasty. Arch Ophthalmol 1987: 105: 646-50.

23 Brown RH, Stewart RH, Lynch MG. Crandal AS, Mandell AI, Wilensky JT. ALO 2145 reduces the intraocular pressure elevation after anterior segment laser surgery. Ophthalmology 1988: 95: $378-84$. 
24 Cyrlin MN. Beckman H. Low dose oral glycerin for the prevention of post laser pressure elevation. ARVO Abstracts. Invest Ophthalmol Vis Sci 1987; 28 (suppl): 272.

25 Brooks AMV, McCombe MF, Elder J, Madhok P, McNab AA, Gillies WE. Preventing a high rise in intraocular pressure after laser trabeculoplasty. Aust NZ J Ophthalmol 1987; 15: 113-7.

26 Ruderman JM, Zweig KO, Wilensky JT, Weinreb RN. Effects of corticosteroid pretreatment on argon laser trabeculoplasty. Am J Ophthalmol 1983; 96: 84-9.

27 Pappas HR, Berry DP, Partamian L, Hertzmark E, Epstein DL. Topical indomethacin therapy before argon laser trabeculoplasty. Am J Ophthalmol 1985; 99: 571-5.

28 Gelfand YA, Wolpert M. Effects of topical indomethacin pretreatment on argon laser trabeculoplasty: a randomised, double-masked study on black South Africans. Br J Ophthalmol 1985: 69: 668-72.

29 Tuulonen A. The effect of topical indomethacin on acute pressure elevation of laser trabeculoplasty in capsular glaucoma. Acta Ophthalmol (Kbh) 1985; 63: 245-9.

30 Hotchkiss ML, Robin AL, Pollack IP, Quigley HA. Nonsteroidal anti-inflammatory agents after argon laser trabeculoplasty. A trial with flurbiprofen and indomethacin. Ophthalmology 1984; 91: 969-76.

31 Weinreb RN, Robin AL, Baerveldt G, Drake MV, Bluthental M, Wilensky J. Flurbiprofen pretreatment in argon laser trabeculoplasty for primary open-angle glaucoma. Arch Ophthalmol 1984: 102: 1629-32.

32 Krupin T, Kolker AE, Kass MA, Becker B. Intraocular pressure the day of argon laser trabeculoplasty in primary open-angle glaucoma. Ophthalmology 1984: 91: 361-5.

33 Leung KW, Gillies WE. The detection and management of the acute rise in intraocular pressure following laser trabeculoplasty. Aust NZ J Ophthalmol 1986; 14: 259-62.

34 Frucht J, Bishra S, Ticho U. Early intraocular response following laser trabeculoplasty. Br J Ophthalmol 1985; 69: 771-3.

35 Friedland BR. Mallonee J, Anderson DR. Short-term dose response characteristics of acetazolamide in man. Arch Ophthalmol 1977; 95: 1809-12.

36 Ellis PP, Price PK, Kelmenson R, et al. Effectiveness of generic acetazolamide. Arch Ophthalmol 1982; 100: 1920-2.

37 Kumura S, Thygeson P. Hogan MJ. Signs and symptoms of uveitis: 1. Anterior uveitis. Am J Ophthalmol 1959: 47: 155-70.

38 Eakins KE. Increased intraocular pressure produced by prostaglandins $\mathrm{E}_{1}$ and $\mathrm{E}_{2}$ in the cat eye. Exp Eye Res 1970; 10: 87-92.

39 Koss MC, March WF, Nordquist RE, Gherezghiher T. Acute intraocular pressure elevation produced by argon laser trabeculoplasty in the cynomolgus monkey. Arch Ophthalmol 1984; 102: 1699-703.

Accepted for publication 28 December 1988. 